\title{
NLRP3, IL-1 $\beta$, and Caspase-1 Gene Transcript Identification and Expression by QCM-D in Obese Children
}

\author{
Modesto Gómez López, ${ }^{1}$ Nadia Mabel Pérez-Vielma $\left(\mathbb{D}^{2}{ }^{2}\right.$ Haydee González Martínez, ${ }^{3}$ \\ Eleazar Lara Padilla, ${ }^{4}$ Cindy Bandala, ${ }^{4}$ María Cristina González Torres, ${ }^{5}$ \\ and Ángel Miliar-García $\mathbb{D}^{1,2}$ \\ ${ }^{1}$ Laboratorio de Biología Molecular, Escuela Superior de Medicina, Instituto Politécnico Nacional, Plan de San Luis y Díaz Mirón, \\ C.P. 11340 Ciudad de Mexico, Mexico \\ ${ }^{2}$ Centro Interdisciplinario de Ciencias de la Salud Unidad Santo Tomás, Instituto Politécnico Nacional, Avenida de los Maestros, \\ C.P. 11340 Ciudad de Mexico, Mexico \\ ${ }^{3}$ Centro de Nanociencias y Micro y Nanotecnologías, Instituto Politécnico Nacional, Av. Luis Enrique Erro, \\ C.P. 07738 Ciudad de Mexico, Mexico \\ ${ }^{4}$ Sección de Estudios de Posgrado e Investigación, Escuela Superior de Medicina, Instituto Politécnico Nacional, Plan de San Luis y \\ Díaz Mirón, C.P. 11340 Ciudad de Mexico, Mexico \\ ${ }^{5}$ Laboratorio de Biología Celular, Universidad Autónoma Metropolitana-Iztapalapa, Av. San Rafael Atlixco, \\ C.P.09340 Ciudad de Mexico, Mexico
}

Correspondence should be addressed to Ángel Miliar-García; amillarg@ipn.mx

Received 20 September 2018; Revised 10 January 2019; Accepted 5 March 2019; Published 17 April 2019

Academic Editor: Roberto Paolesse

Copyright (C) 2019 Modesto Gómez López et al. This is an open access article distributed under the Creative Commons Attribution License, which permits unrestricted use, distribution, and reproduction in any medium, provided the original work is properly cited.

\begin{abstract}
Background. Obesity in children is highly prevalent in Mexican population. Adipose tissue has been related to specific pro- and anti-inflammatory cytokine and inflammasome gene and protein expression patterns. Actually, there is no existing biosensor for detecting gene expression patterns in children with obesity. The quartz crystal microbalance with dissipation monitoring (QCM-D) has been used as a transducer for DNA biosensor design. Results. In this study, the gene expression pattern of $I L-1 \beta$, NLRP3, and CASPASE-1 in children with obesity was successfully determined by means of QCM-D. Gene expression patterns were validated with those obtained by quantitative polymerase chain reaction (qPCR), a validated molecular biology technique for gene expression quantification. QCM-D analysis of the detected mass corresponding results for each of the genes showed a major detected mass for $I L-1 \beta$, followed by similar $N L R P 3$ and constitutive gene $18 S$ deposited mass and a smaller deposited mass for CASPASE-1. Surprisingly, when comparing mRNA gene expression results for NLRP3, IL-1 $\beta$, and CASPASE-1 obtained with qPCR and QCM-D, similar patterns were found, revealing greatest expression of $I L-1 \beta$, followed by $N L R P 3$, with CASPASE- 1 being the molecule of least expression in the group of children with obesity. AFM images illustrate the step-by-step changes that took place on the quartz surface. Conclusions. QCM-D proved successfully for determining the gene transcripts and expression of NLRP3, IL-1 $\beta$, and CASPASE-1 in children with obesity, with similar results validated by qPCR. "QCM-D decreases detection costs compared with a validated molecular biology technique." The QCM-D biosensor developed by our group was successful for gene expression determination; in the future, it can be used for molecular diagnosis.
\end{abstract}

\section{Introduction}

Quartz crystal microbalance with dissipation monitoring (QCM-D) is a mass-sensitive transducer that provides the opportunity to analyze the interactions between molecules at solid/liquid interfaces. The advantages of the QCM-D on its application in the analysis of interaction mechanisms comprise high sensitivity, in situ, nearly real-time monitoring, and simultaneous mass and viscoelastic measurement [1]. QCM-D advantages render it suitable for the development 
of biosensors, especially DNA and RNA biosensors. Currently, the techniques used for gene expression determination that have greater specificity are qualitative polymerase chain reactions (qPCR) and microarrays. However, these techniques are time-consuming and expensive. Affinity-based biosensors may represent an alternative tool able to quantify the expression of a set of selected genes by determining the amount of corresponding messenger RNA (mRNA) in complex mixtures. The advantages of this approach include avoiding the labelling, retrotranscription, and amplification steps while maintaining high sensitivity and specificity [2-4]. Mass-sensitive biosensors have attracted considerable attention in recent years due to their simplicity, low instrumentation costs, high sensitivity, and the possibility of performing real-time and free labelling detection. The QCM-D system belongs to mass-sensitive biosensors. Its operating principle relies on the piezoelectric crystal properties: the resonant frequency shifts are directly proportional to the adsorbed mass $[2,5]$. Quartz crystal microbalance (QCM) is suitable for biosensors, including DNA biosensors. Lucarelli and colleagues implemented a QCM biosensor for the detection of a singlebase DNA mutation, while the Jearanaikoon's group built a QCM-D biosensor to monitor conformational changes during DNA hybridization $[4,6]$. Song et al. measured in real-time human papillomavirus 16 DNA through a loopmediated isothermal amplification-QCM biosensor [7]. Bunroddith and colleagues developed a QCM sensor for the ultrasensitive detection of DNA with results comparable to the ones obtained using a SPR sensor platform [8]. Ravi et al. reported a rapid screening method of Ehrlichia canis PCR amplification products based on PCR assay combined with QCM [9]. Regarding RNA biosensors, Tedeschi and coworkers reported that they successfully achieved a QCM label-free RNA biosensor with high specificity, reusability, and the ability to provide quantitative information [2]. There are reports about cDNA quantification and gene expression biosensor development. Han et al. reported a cDNA quantification platform using a giant magnetoresistive (GMR) biosensor array [10], meanwhile Papadakis et al. designed an electrochemical platform for direct detection of CYP707A1 gene expression from wheat leaves [11]. Davis et al. developed a biosensor for SNP genotyping and gene expression quantification combining conventional PCR for target amplification and QCM for amplicon detection [12]. Nevertheless, there are no reports of a biosensor that determine neither gene transcripts nor their expression in children with obesity.

Obesity is considered a risk factor for different comorbidities and has been related with high morbidity and mortality [13-15]. It has been shown that obesity is a state of chronic inflammation characterized by macrophage infiltration and that the gene expression of molecules related with proinflammatory processes plays an important role during development of the disease [16]. In Mexican population, obesity prevalence has increased very fast; it is estimated that in 2050, more than one half of the adult population will suffer from obesity $(54 \%)[13,15,17]$. Immune response varies with respect to the life stage [18]: in children and adults with obesity, cytokines IL-1 $\beta$ and NLRP3 are elevated $[19,20]$. It has been reported that adipose tissue in obese population influences the secretion of pro- and anti-inflammatory cytokines such as tumor necrosis factor alpha (TNF- $\alpha$ ), interleukin 1 (IL-1), IL-8, caspase, and inflammasomes; the secretion of these molecules promotes comorbidities such as type 2 diabetes, steatosis, and cardiovascular diseases $[13,16,21]$. Therefore, the goal of the present work was to identify NLRP3, IL-1 $\beta$, and CASPASE 1 (CASP-1) gene transcripts, as well as their expression, from the blood samples of children with obesity by means of QCM-D biosensors. Precisely, the novelty of this biosensor lies in the identification of gene transcripts and their expression, which is of vital importance for the molecular diagnostic of different pathologies.

\section{Methods}

2.1. Patients and Blood Samples. This protocol was approved by the Ethics and Research Committees of the Escuela Superior de Medicina (ESM-CE-01/03-12-2013). Written and informed consent was obtained from all participants. The trial was conducted in accordance with the ethical principles originating in the Declaration of Helsinki and it was consistent with Good Clinical Practice Guidelines (GCPG). Body mass index (BMI) was utilized to classify the patients. Patients were randomized in a group of children with obesity $(n=30)$. A sample of blood $(4 \mathrm{~mL})$ was obtained from the antecubital vein of the child's arm and used for RNA extraction. These samples were employed for determining the gene transcripts and expression of NLRP3, IL-1 $\beta$, and CASP-1.

2.2. RNA Extraction and cDNA Synthesis. Human RNA was isolated using the TRIzol reagent according to the manufacturer's instructions (TriPure Isolation Reagent; Roche Applied Science, Indianapolis, IN, USA). The amount and purity of RNA was quantified nanophotometrically by measuring optical density (OD) at 260 and $280 \mathrm{~nm}$. Integrity was checked for all samples by agarose gel electrophoresis. To avoid trace amounts of DNA contamination, RNA samples were treated with amplification-grade DNase I (Invitrogen, Carlsbad, CA, USA) before reverse transcription. All RNA samples were stored at $-80^{\circ} \mathrm{C}$ in RNA elution solution. The first-strand cDNA Synthesis Kit (Roche Diagnostics, GmbH Mannheim, Germany) was utilized, taking $1 \mu \mathrm{g}$ of the total sample RNA; reverse transcription was performed with random hexamers primers following the instructions specified by the manufacturer, in an Eppendorf thermocycler. Finally, cDNA concentration, obtained from human RNA, was determined through nanospectrophotometric measurement. This cDNA was used as capture probe for the QCM-D biosensor experiments.

\subsection{Surface Chemistry, cDNA Immobilization, and QCM-D} Hybridization Assays. The reagents used for the surface chemistry over gold were 6-mercapto-1-hexanol (MCH), $\mathrm{N}$-(3-dimethylaminopropyl)- $\mathrm{N}^{\prime}$-ethylcarbodiimide hydrochloride (EDC), N-hydroxysuccinimide (NHS), and PBS 10X buffer, $\mathrm{pH}$ 7.4. All reagents for the surface chemistry were purchased from Sigma-Aldrich, Mexico. All chemicals were reagent grade and utilized without further purification. We used quartz crystals (Q-Sense sensors) coated with 
$100 \mathrm{~nm}$ gold thin film for the QCM-D experiments, with a frequency of $4.95 \mathrm{MHz} \pm 50 \mathrm{kHz}$, cut $\mathrm{AT}$, a diameter of $14 \mathrm{~mm}$, a thickness of $0.3 \mathrm{~mm}$, optically polished, and purchased from Biolin Scientific Inc., USA. QCM-D experiments were performed in a Q-Sense E4. The quartz crystals were washed with (type 1 water, ammonia, and hydrogen peroxide) HPA solution and placed into ultraviolet (UV) ozone. After this, they were incubated in a $1 \mathrm{mM} \mathrm{MCH}$ solution and isolated from light for $48 \mathrm{~h}$ at room temperature. Once incubation was completed, the quartz crystals were washed with ethanol and dried with nitrogen flux. The quartz crystals were then incubated for $2 \mathrm{~h}$ in PBS $10 \mathrm{X}(2.5 \mathrm{~mL})$ with $5 \mathrm{mM}$ EDC $(0.024 \mathrm{~g})$ and $8 \mathrm{mM}$ NHS $(0.023 \mathrm{~g}), \mathrm{pH} 8$. The functionalized quartz crystals were placed in the QCM-D, and water was injected for $1 \mathrm{~h}$ to stabilize the frequencies and dissipations. Next, a previously denaturalized $3.5 \mathrm{ng}$ concentration of cDNA corresponding to the genes NLRP3, $I L-1 \beta, C A S P-1,18 S$ (positive control), and NLRP10 specific for rat (negative control) was injected into each of the QCM-D modules and incubated for $2 \mathrm{~h}$. In order to achieve this concentration, a pool of the cDNA samples of the children with obesity was employed. After, the quartz crystal surfaces were exposed to UV light for $3 \mathrm{~min}$ by using a UV transilluminator (Stratalinker UV). Finally, specific oligonucleotides designed to hybridize with each of the capture probe cDNAs were injected in the corresponding QCM-D modules for hybridization for $1 \mathrm{~h}$. The specific oligonucleotides used in the QCM-D hybridization assays were NLRP $3,5^{\prime}$-CACCTGTTGTGCAATCTGAAG-3' (forward) and $5^{\prime}$-GCAAGATCCTGACAACATGC- $3^{\prime}$ (reverse); IL$1 \beta, 5^{\prime}$-CTGTCCTGCGTGTTGAAAGA-3' (forward) and $5^{\prime}$-TTGGGTAATTTTTGGGATCTAC- $3^{\prime}$ (reverse); CASP1, $5^{\prime}$-GCGAAGCATACTTTCAGTTTC- ${ }^{\prime}$ (forward) and $5^{\prime}$-TCTCCTTCAGGACCTTGTCG-3' (reverse); 18S, $5^{\prime}$ -CGAACGTCTGCCCTATCAAC- $3^{\prime}$ (forward) and $5^{\prime}$ -TTGGATGTGGTAGCCGTTTC-3' (reverse); and NLRP10 specific for rat, 5' -TCAACCAGGTTTGTCTGAATGA-3' (forward) and $5^{\prime}$-CTGTTTACACCCCAATCTTGC-3 (reverse). The standardized concentration of these oligonucleotides for the QCM-D hybridization assays was $3.5 \mathrm{ng} / \mu \mathrm{L}$. This functionalization was specifically designed to allow bonding of cDNA obtained directly from human RNA without any label or chemical modification (patented by our group: MX/E/2014/057816). The corresponding data for mass and changes in frequency was registered continuously during the entire experiment. QCM-D hybridization assays for each of the genes were done in triplicate. The results obtained were analyzed with QTools software from Q-Sense.

2.4. Atomic Force Microscopy (AFM). Finally, the topography of the functionalized, anchored, hybridized, and treated with DNase quartz crystals was explored using AFM. DNase in an enzyme degrades DNA exclusively; thus, DNase treatment allows verifying that the molecule attached is DNA. The AFM instrument used was a diMultiMode from Veeco (Santa Barbara, CA) in contact air mode with diNanoScope V controller, using RTESPA tips. All the images were visualized and analyzed using the NanoScope analysis software.
2.5. Real-Time Quantitative Polymerase Chain Reaction ( $q P C R)$. In this research, qPCR was used as a molecular biology validation technique; $\mathrm{qPCR}$ is a validated method used in molecular biology to determine genic expression [22, 23]. qPCRs were carried out using specific oligonucleotide primers that were originally generated by using online assay design software (https://qpcr.probefinder.com/organism .jsp). In order to compare and validate the results obtained in the QCM-D hybridization assays, the specific oligonucleotides used were the same in both methods. The reaction mixture was prepared according to the manufacturer's instructions (Roche Diagnostics, GmbH) utilizing $1 \mu \mathrm{L}$ of standard cDNA at the appropriate dilution. The amplification was performed in LightCycler 8-Tube Strips (Roche Diagnostics) with a LightCycler nanoinstrument. Amplification conditions for the Universal ProbeLibrary- (UPL-) based assays were initially denaturized for $10 \mathrm{~min}$ at $95^{\circ} \mathrm{C}$, followed by 45 cycles of $10 \mathrm{~s}$ at $94^{\circ} \mathrm{C}$, of $20 \mathrm{~s}$ at $60^{\circ} \mathrm{C}$, and of $5 \mathrm{~s}$ at $72^{\circ} \mathrm{C}$. The qPCR assays included the standard curve of four serial dilution points for each gene, and mRNA levels were calculated by employing the comparative parameter threshold cycle $(\mathrm{Ct})$ method and normalized to the endogenous control: $18 \mathrm{~S}$ mRNA. qPCR experiments require a standardization of the reaction efficiency curves for gene expression. In the formula to standardize the results $\left(2^{\Delta \Delta \mathrm{Ct}}\right)$, number two corresponds to the qPCR efficiency reaction (dynamic range curve or dilutions of the constitutive gene). According to the guidelines and specifications of the Roche Nano Thermal Cycler software, the efficiency must be 2, so it is necessary to make serial dilutions of a sample chosen randomly from an experiment. These logarithmic dilutions estimate the accuracy of the concentration. Results were calculated as a percentage of the mean level found in control using the $\Delta \mathrm{Ct}$ method.

The qPCR primer pairs used for amplifying the NLRP3, $I L-1 \beta$, and $C A S P-1$ fragments were the same as the ones used for the QCM-D hybridization assays. Finally, the results of the genic expression are expressed as the mean \pm standard deviation (SD). Gene expression and deposited mass data were analyzed with one-way analysis of variance (ANOVA), and the comparison between the anchored DNA and the hybridization assay was analyzed using the Student $t$-test from SigmaPlot ver. 12.0 software (San Jose, CA, USA), while differences were considered statistically significant when $p \leq 0.05$.

\section{Results and Discussion}

3.1. Gene Transcript Identification and Expression by QCM-D. The first step to achieving the goal of this work was to accomplish a stable functionalization based on $\mathrm{MCH}$ over the QCM sensors, obtaining covalent bonds between the gold surface and the cDNA, as shown in Figure 1. For covalent binding of cDNA target, the crystal surfaces were exposed to $254 \mathrm{~nm}$ UV light with a power of $23 \mathrm{~mW} / \mathrm{cm}^{2}$ for $3 \mathrm{~min}$ by using a UV transilluminator (Stratalinker UV). The positively charged carbon atom in carbodiimides rapidly reacts with the partially negatively charged oxygen in the $5^{\prime}$-phosphate group forming an active phosphodiester. 


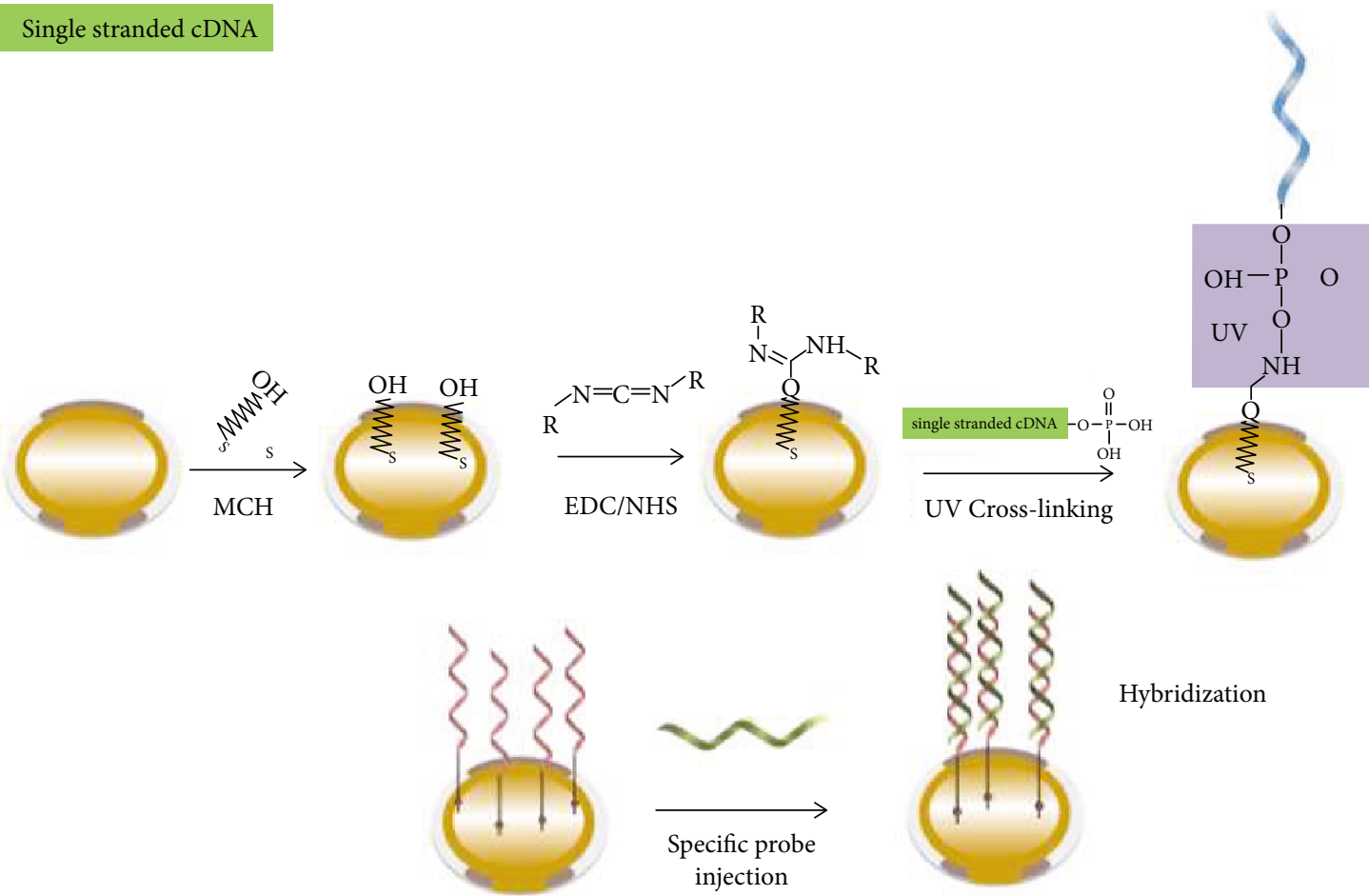

FIgURE 1: cDNA immobilization on the QCM gold surface. In Figure 1, the quartz crystal surface chemistry based on a MCH SAM formation step by step is shown. Once the quartz crystal was functionalized, the cDNA obtained from human RNA was immobilized and hybridized with each of the oligonucleotides designed specifically for each of the genes tested in the QCM-D.

After the quartz crystals were functionalized, the hybridization assays of the NLRP3, IL-1 $\beta$, and CASP-1 genes were performed by means of the QCM-D. In the hybridization assays, all the harmonics were used to keep track of the changes in frequency and dissipation changes. One of the sensors was utilized as a control sensor in which type 1 water was hybridized. The results of this sensor, shown in Figure 2, revealed no changes in frequencies and dissipations when the QCM-D module was filled with type 1 water (for the initial hybridization analysis, the technical specifications of the QCM-D suggested the use of the harmonics 5, 7, and 9 avoiding noise signals). This means that there was no deposition of nucleic acids interacting with the functionalized surface.

Once no interaction with the functionalized surface of the control sensor was proven, hybridization assays with the respective genes were performed. QCM-D hybridization assays for each gene were done in triplicate. First, the hybridization assay of the NLRP3 gene was carried out. The results of the NLRP3 gene hybridization assay are shown in Figure 3. cDNA was anchored during the first $2 \mathrm{~h} 46 \mathrm{~min}$, reflecting changes in frequencies ( 2.5 to $-0.3,2.2$ to 0.1 , and -0.3 to $0.6 \mathrm{~Hz}$, respectively). Later, the respective oligonucleotides were injected for hybridization with NLRP3 gene-specific oligonucleotides, obtaining a decrease in the frequencies ( 0.6 to $-9.8,0.1$ to -8.7 , and -0.3 to $-7.5 \mathrm{~Hz}$ ) and dissipations ( 0 to $0.38,0.1$ to 0.26 , and 0 to 0.1 ). Figure 3 (b) depicts an increase in the deposited mass concentration in each of the phases. On the other hand, the viscoelasticity of the sample increased as the amount of mass deposited increased. When plotting mass quantity at different times of the sample deposit (S1 supplementary materials), a significant increase $(p<0.001)$ in the deposited mass at the time of hybridizing the bonded cDNA with the NLRP3 oligonucleotides was observed. Viscoelasticity increased (S2 supplementary materials) upon hybridization with cDNA $(p=0.001)$.

The second hybridization assay was conducted with the IL- $1 \beta$ gene. These results are shown in Figure 4. From time 0-2 h $46 \mathrm{~min}$, cDNA immobilization (Figure 4(a)) was accomplished. A decrease in the respective frequencies is observed (ranging from 0.3 to -3.0 to -3 and 0 to $-2 \mathrm{~Hz}$ ) when anchoring the cDNA, as well as when hybridizing the oligonucleotides with the IL- $1 \beta$ gene $(-3$ to $-14,-3$ to -12 , and $-10.5 \mathrm{~Hz}$ ). An increase in dissipation was also reported when anchoring the cDNA ( 0 to $0.22,-0.2$ to 0.3 , and 0.1 to 0.2 ), as well as when the specific oligonucleotides for hybridizing the IL- $1 \beta$ gene were injected ( 0.22 to $3.4,0.3$ to 2.8 , and 0.2 to 2.2). An increase in mass deposition on the quartz crystal $(p=0.001)$ was observed when graphing the data, as well as an increase in viscoelasticity $(p=0.05)$ (S3 and S4 supplementary materials).

The results of the CASP-1 gene hybridization assay are presented in Figure 5. From time 0 to $2 \mathrm{~h} 46 \mathrm{~min}$, immobilization of the cDNA demonstrates a decrease in frequencies in the different harmonics ( 4 to $2.5,3$ to 1.5 , and 1.5 to -0.3$)$. At the time of hybridization with the specific oligonucleotides for the CASP-1 gene, a decrease in frequencies is also observed ( 2.5 to $-3,1.5$ to -5.5 , and -0.3 to -8.5 ). On the other hand, the dissipations increased when anchoring the cDNA ( 0 to $0.22,-0.2$ to 0.3 , and 0.1 to 0.2 ) for each harmonic and when hybridizing with the CASP-1 gene 


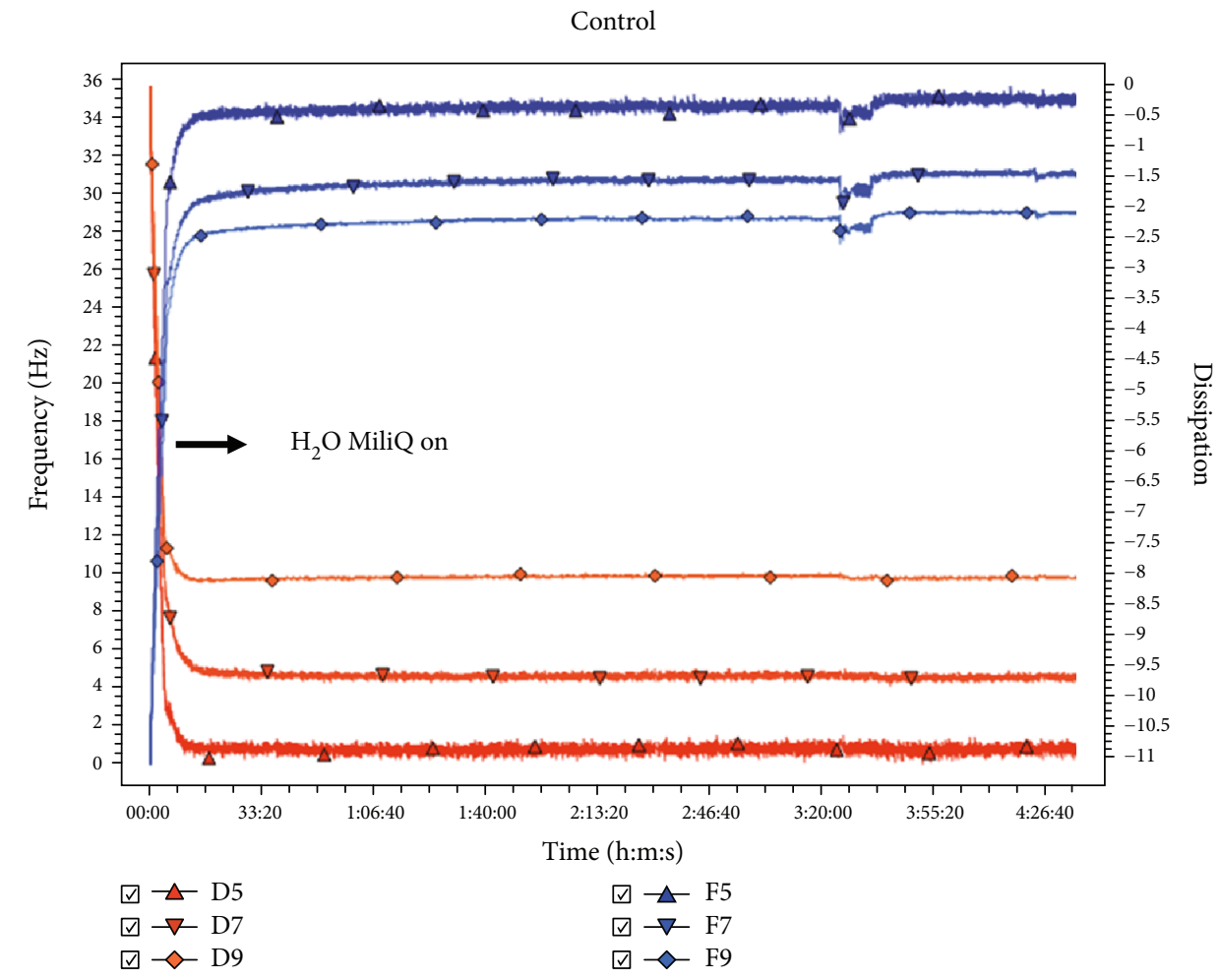

FIgURE 2: QCM-D. Data obtained from the analysis of the control sensor. Type 1 water was injected; no changes in frequency $(\Delta F)$ nor dissipation $(\Delta D)$ were detected over the functionalized gold surface when the sample was set in place.

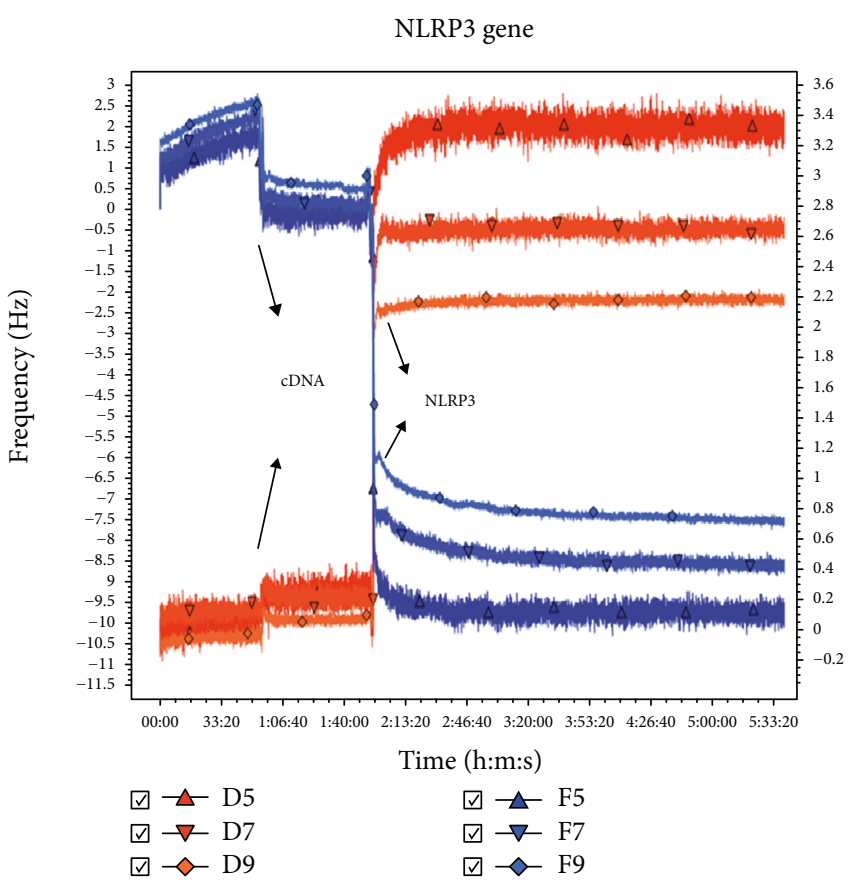

(a)

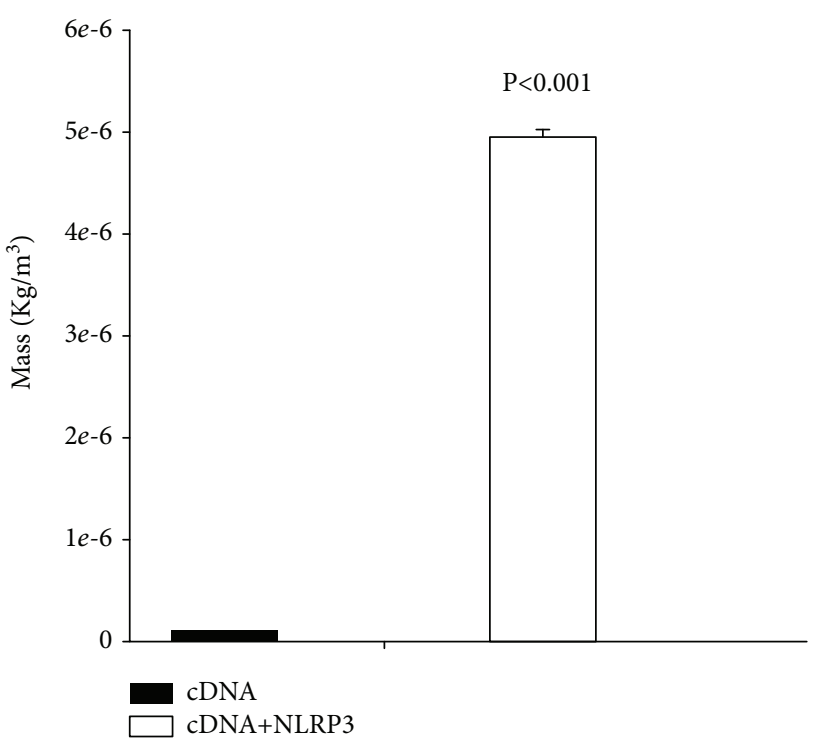

(b)

FIgURE 3: Monitoring of anchorage of the cDNA anchorage and hybridization with NLRP3 oligonucleotides by means of the QCM-D. The first phase reveals changes in dissipation $(\Delta D)$ and frequency $(\Delta F)$ when cDNA was anchored, followed by hybridization with NLRP3-specific oligonucleotides (a). In graph (b), the deposited mass is plotted in each of the phases. 


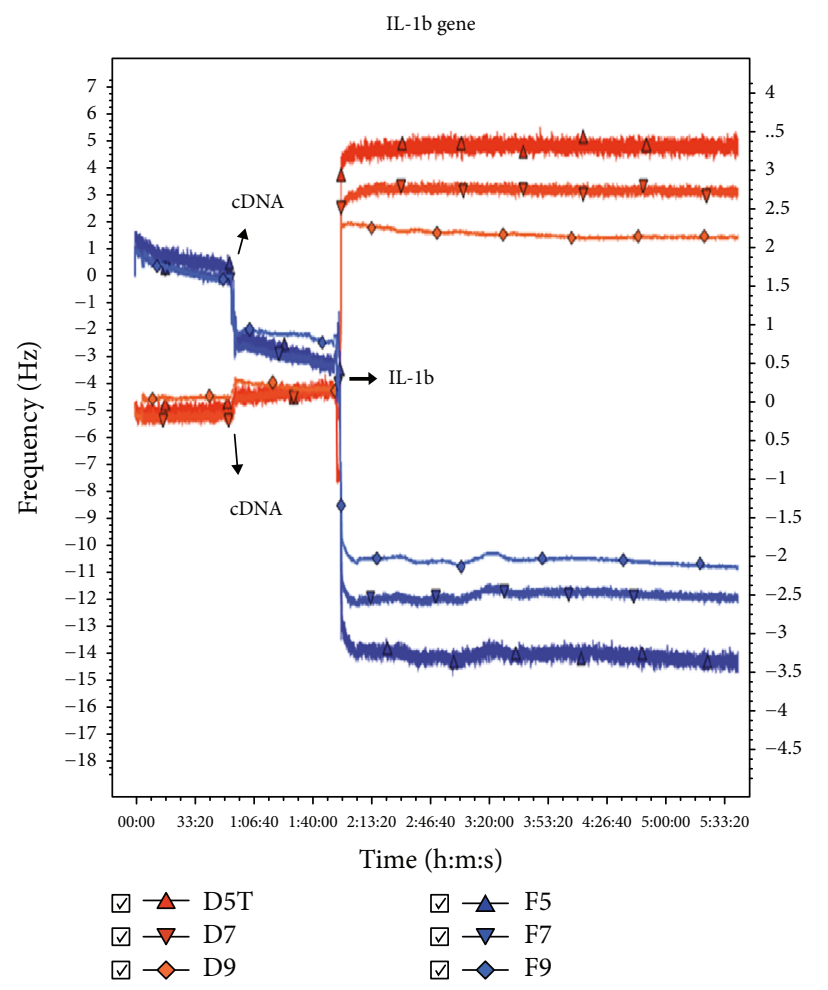

(a)

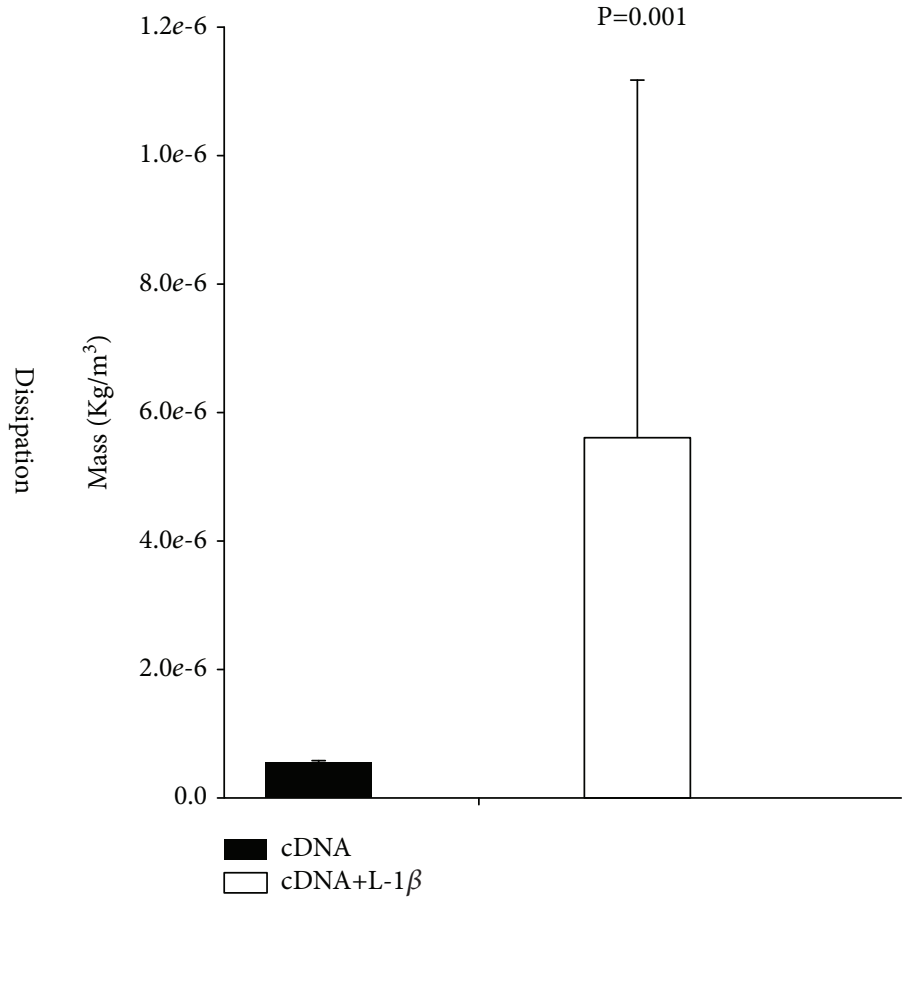

(b)

FIGURE 4: Monitoring the anchoring and hybridization of cDNA and $I L-1 \beta$ (oligonucleotide) by means of QCM-D. In a first phase, changes in dissipation $(\Delta D)$ and frequency $(\Delta F)$ are reported on anchoring cDNA, followed by hybridization with IL- $1 \beta$.

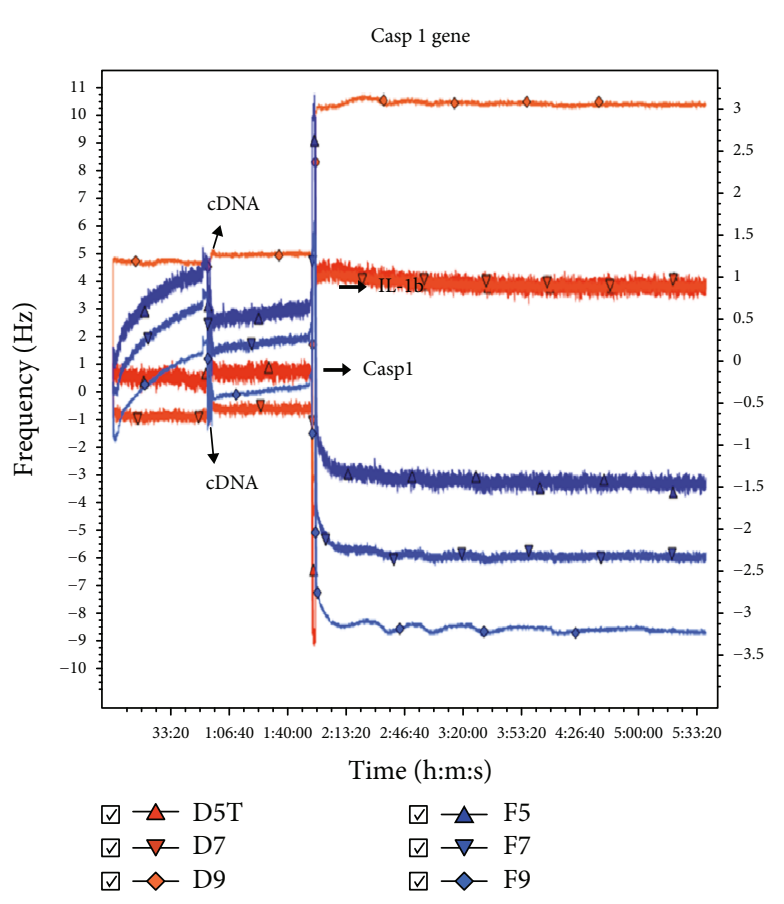

(a)

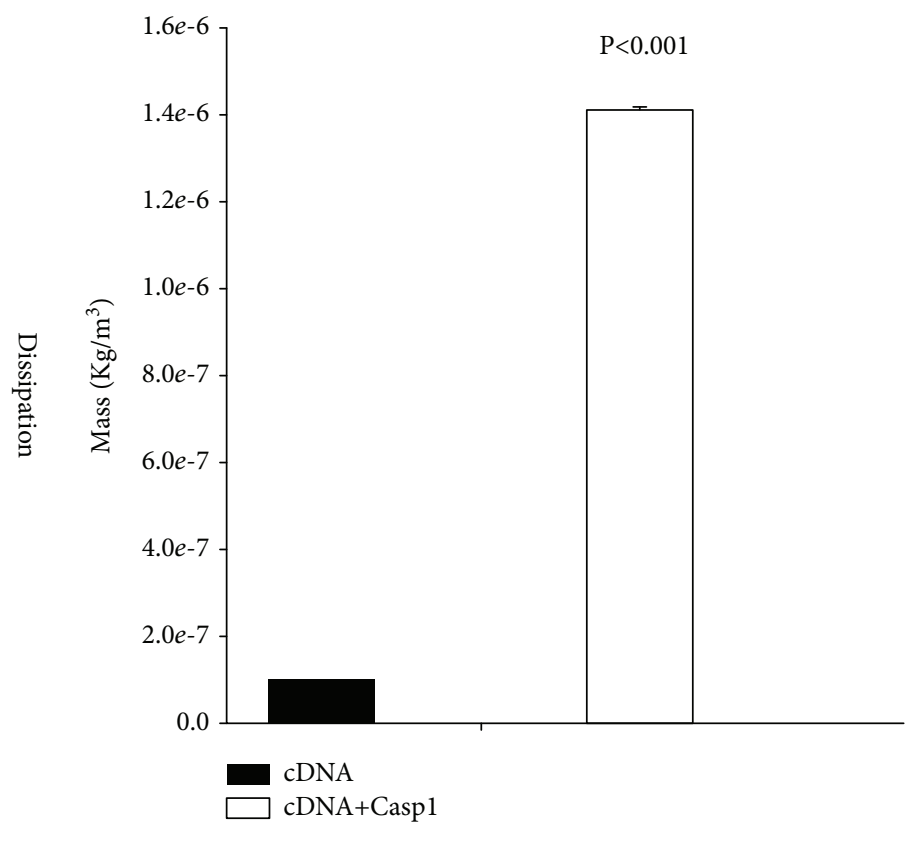

(b)

FIGURE 5: Monitoring the anchoring and hybridization of cDNA and CASP-1-specific oligonucleotides by means of QCM-D. In a first phase, changes of dissipation $(\Delta D)$ and frequency $(\Delta F)$ when anchoring cDNA are depicted, followed by hybridization with CASP-1 (a). In (b) deposited mass is plotted. 
oligonucleotides ( 0.22 to $3.4,0.3$ to 2.8 , and 0.2 to 2.2$)$. In addition, an increase in mass concentration both when anchoring the cDNA and when hybridizing with the specific oligonucleotides was observed (Figure 5(b)), as well as an increase in viscoelasticity. By plotting the deposited mass values (S5 supplementary materials), significant differences in mass increase can be noted by hybridizing with the specific oligonucleotides for CASP-1 $(p=0.001)$. Otherwise, in Figure S6 supplementary materials, an increase in viscoelasticity can be noted $(p=0.012)$.

In order to prove the specific hybridization, the constitutive gene $18 \mathrm{~s}$ of eukaryotic cells was tested as positive control and the NLRP10 rat gene that encodes exclusively for the rat genome as negative control. The results of the $18 \mathrm{~S}$ gene hybridization assay are demonstrated in Figure 6(a). From time 0 to $2 \mathrm{~h} 30 \mathrm{~min}$, cDNA bonding took place, and a decrease in the frequencies was observed ( 0 to $-3.2,-0.2$ to -3.8 , and -0.2 to $-3.2 \mathrm{~Hz}$ ). Subsequently, specific oligonucleotides were injected to hybridize with the constitutive $18 \mathrm{~s}$ gene, revealing a decrease in frequencies $(-3.2$ to -7.8 , -3.8 to -7.8 , and -3.2 to $-8 \mathrm{~Hz}$ ) and an increase in dissipations when anchoring the cDNA $(-1.1$ to $-0.4,-0.14$ to -0.2 , and -0.24 to $0.02 \mathrm{~Hz}$ ), as well as when hybridizing with the specific oligonucleotides for $18 \mathrm{~S}(-0.02$ to $0.08,-0.2$ to 0.2 , and -0.4 at $0.1 \mathrm{~Hz}$ ). Figure $6(\mathrm{~b})$ presents an increase in deposited mass concentration and low viscoelasticity. On the other hand, when plotting mass deposition on quartz (S7 supplementary materials), a statistically significant increase in mass deposition $(p=0.001)$ and an increase in viscoelasticity $(p=0.001)$ (S8 supplementary materials) were observed.

Figure 7 (a) presents the results of the NLRP10 rat gene hybridization assay. From time 0 to $2 \mathrm{~h} 46 \mathrm{~min}, \mathrm{cDNA}$ immobilization was reported by finding decreases in frequencies ( -250 to $-252,-210$ to -212 , and -182 to $-183 \mathrm{~Hz}$ ), and hybridization with NLRP10 oligonucleotides also reported a decrease in the frequencies $(-252$ to $-255,-212$ to -215 , and -183 to $-186 \mathrm{~Hz}$ ). Figure $7(\mathrm{~b})$ demonstrated low concentration in the mass detected after $2 \mathrm{~h}$. No significant changes were observed at the time of plotting mass and viscoelasticity ( 99 and S10 supplementary materials).

Once realized the QCM-D hybridization assays of all tested genes (NLRP3, IL-1 $\beta, C A S P 1,18 S$, and NLRP10-Rat), the number of molecules $(N)$ on the surface of the quartz was calculated using the Sauerbrey equation [18], considering the frequency shifts and mass changes on the surface. As shown in Table 1 , IL- $1 \beta$ presents the greatest number of immobilized and hybridized molecules, followed by $18 \mathrm{~S}$ (positive control) and NLRP3, being CASP-1 the one with the least molecules immobilized and hybridized. On the other hand, the negative control NLRP10-rat showed no molecules attached.

3.2. Atomic Force Microscopy (AFM). The images of the different quartz crystals in each of the experimental phases were taken with the diMultiMode AFM from Veeco (Santa Barbara, CA) in contact air mode with diNanoScope V controller. As shown in Figure 8(a), there is no visible structure deposited on the quartz, while in Figure 8(b), the deposited
cDNA can be observed, and in Figure 8(c), it can be observed that the cDNA was hybridized with the specific oligonucleotides, which allowed to observe the deposition of nucleic acids with greater compaction than when only cDNA was deposited (Figure 8(b)). In Figure 8(d), the absence of material deposited on the quartz can be observed once it was treated with DNase I, an enzyme that digested the cDNA previously anchored and hybridized.

3.3. Real-Time Quantitative Polymerase Chain Reaction ( $q P C R)$. The gene expression levels of inflammatory genes $N L R P 3, I L-1 \beta$, and $C A S P-1$ were determined from the blood samples of children with obesity. Expression of the genes encoding for NLRP3, $I L-1 \beta$, and CASP-1 demonstrated differential expression in the study group. The expression of mRNA for NLRP3 was statistically increased when compared with that of $I L-1 \beta(p=0.008)$ and CASP-1 $(p=0.041)$, as shown in Figure 9. On the other hand, $I L-1 \beta$ was increased compared to CASP-1, although no statistical differences were found between them, as observed. Figures 9(a) and 9(b) present the correlation between the gene expression results and the mass deposited on the quartz crystal of the NLRP3 gene (first bar), the $I L-1 \beta$ gene (second bar), and the CASP-1 gene (third bar), respectively. Proving that greater the gene expression determined by qPCR greater is the deposited mass detected by QCM-D. This same pattern was observed in the genes that presented lower genetic expression, which showed lower deposited mass. Determining the viscoelasticity for each of the genes allowed proving the hybridization between the DNA complementary strands, S11 (supplementary materials).

QCM-D is a mass-sensitive transducer that provides the opportunity to analyze the interactions among molecules at solid/liquid interfaces. The advantages of the QCM-D, applied in the analysis of interaction mechanisms, are high sensitivity, in situ, real-time monitoring, and simultaneous mass and viscoelastic measurement [1]. QCM-D has been employed to analyze enzymatic reactions, detecting mass changes on the surface $[24,25]$. On the other hand, experiments developed with QCM-D that involved nucleic acids focused on DNA binding, RNA transcription or elongation, and the relationship between RNA polymerase and DNA. Despite that the elongation process has not been well characterized, double-stranded DNA (dsDNA) was immobilized on the quartz surface in order to analyze the transcription reaction. The results showed nanogram-level mass increase and a decrease in frequency in real time [26-28]. Regarding RNA biosensors, Tedeschi et al. successfully achieved a QCM label-free RNA biosensor with high specificity, reusability, and the ability to supply quantitative information. This sensor was able to bind the RNA under investigation through a complementary oligonucleotide probe by means of covalent immobilization [2]. This previous work was very important because it was, to our knowledge, the first report of a RNA biosensor developed using QCM-D. However, synthetic RNA was utilized for the experiments and the authors only proved the binding ability of RNA probes using both a synthetic substrate and full-length "in vitro" transcribed mRNA. Regarding gene expression biosensors, Han et al. developed a 


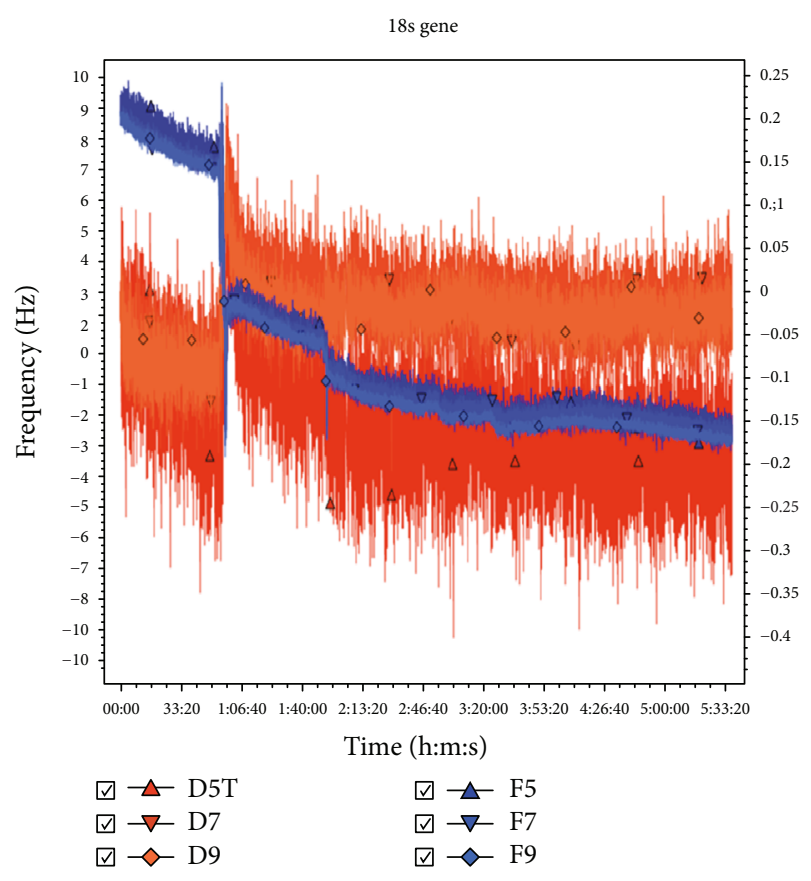

(a)

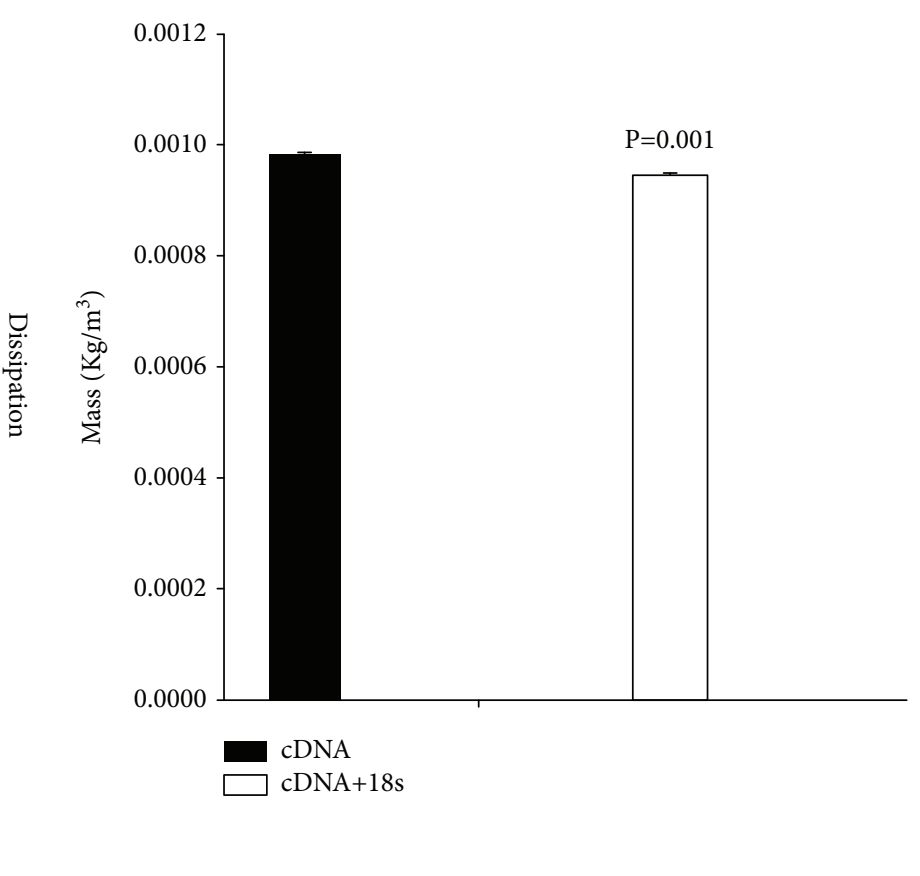

(b)

Figure 6: Monitoring the anchoring and hybridization of cDNA with oligonucleotide $18 S$ by QCM-D. In the first phase, changes in dissipation $(\Delta D)$ and frequency $(\Delta F)$ when immobilizing cDNA are shown, followed by hybridization with $18 \mathrm{~s}$ (a). In (b) deposited mass is plotted.

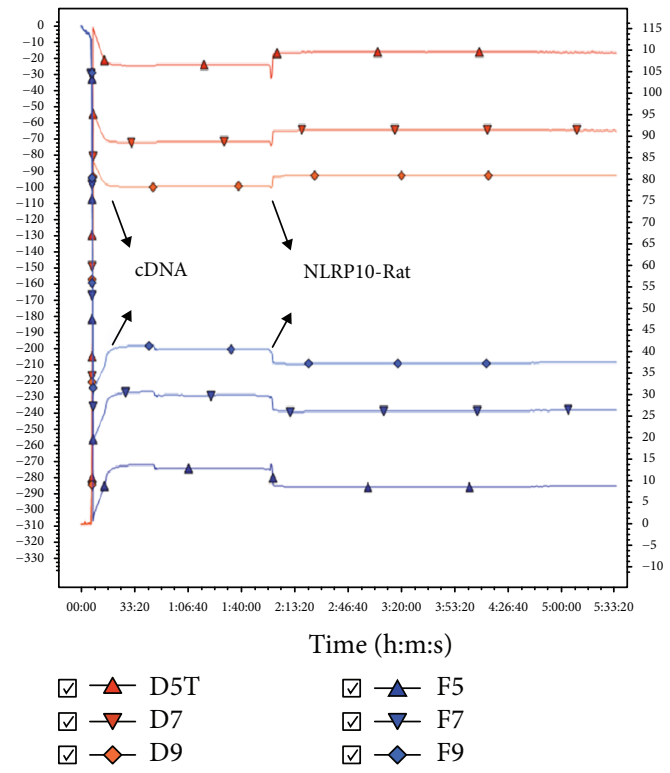

(a)

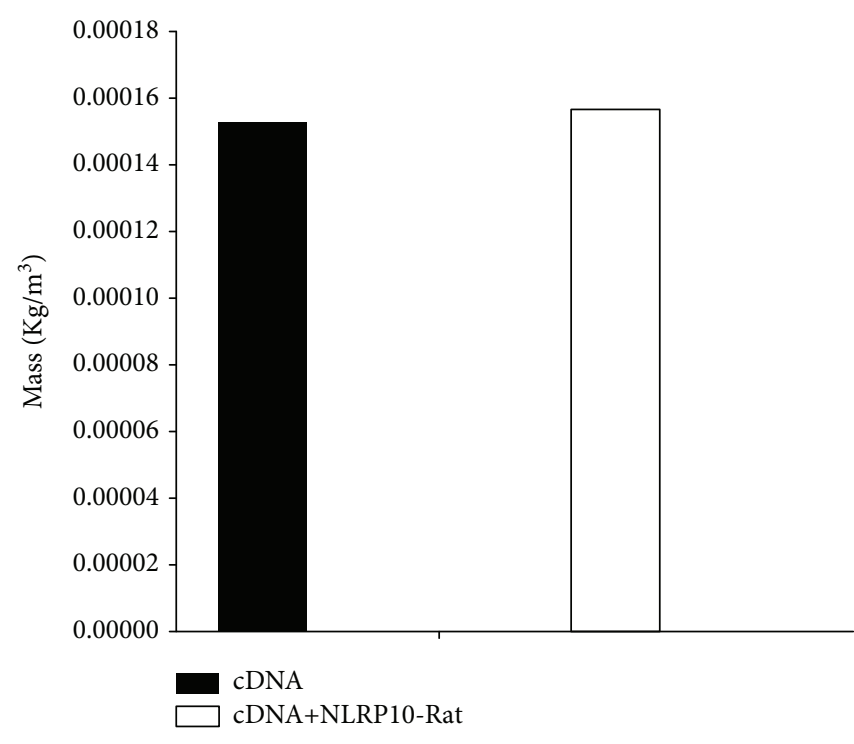

(b)

Figure 7: Monitoring the anchoring and hybridization of cDNA and NLRP10-rat oligonucleotides by QCM-D. In a first phase, dissipation $(\Delta D)$ and frequency $(\Delta F)$ changes are shown when anchoring cDNA, followed by hybridization with NLRP10 (a). In (b) deposited mass is plotted.

cDNA quantification platform using a giant magnetoresistive (GMR) biosensor array. The gene expression analysis relied on hybridization of complementary DNA strands. GMR chips were functionalized with amino-modified ssDNA probes and then spotted with these probes complementary to the GAPDH gene. Total mRNA from HeLa cells was isolated, reverse transcribed, and qPCR amplified with biotinylated primers to create cDNA, which is denatured and applied as ssDNA target to 
TABLE 1: Number of molecules anchored and hybridized for each of the genes tested on the surface of the QCM.

\begin{tabular}{lcccccc}
\hline Base & $M_{\mathrm{w}}$ & Bases/gene (NLRP3) & Bases/gene $(I L-\beta)$ & Bases/gene (CASP-1) & Bases/gene (18S) & Bases/gene (NLRP10-rat) \\
\hline$A$ & 135.1 & 1621.56 & 1081.04 & 945.91 & 945.91 & 1351.3 \\
$T$ & 126.1 & 1135.0197 & 2017.8128 & 1765.5862 & 1513.3596 & 1639.4729 \\
$G$ & 151.1 & 1360.17 & 1813.56 & 1209.04 & 1511.3 & 906.78 \\
$C$ & 111.1 & 1111 & 666.6 & 1333.2 & 1222.1 & 1333.2 \\
Total $M_{\mathrm{w}}$ & & 5227.7497 & 5579.0128 & 5253.7362 & 5192.6696 & 5230.7529 \\
$N$ & & $3.978 E+17$ & $7.8173 E+17$ & $2.1616 E+17$ & $6.4519 E+17$ & $-5.77887 E+18$ \\
\hline
\end{tabular}

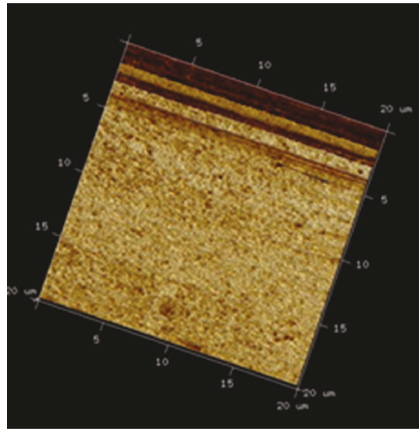

(a)

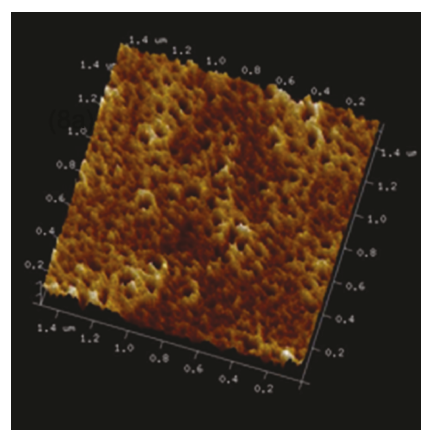

(c)

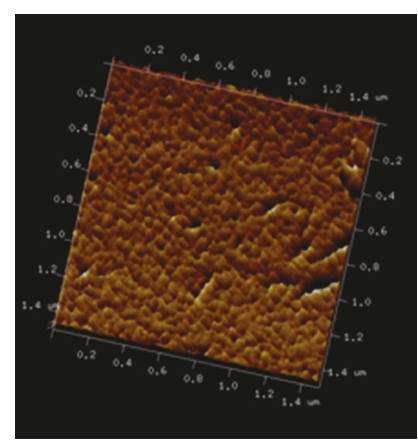

(b)

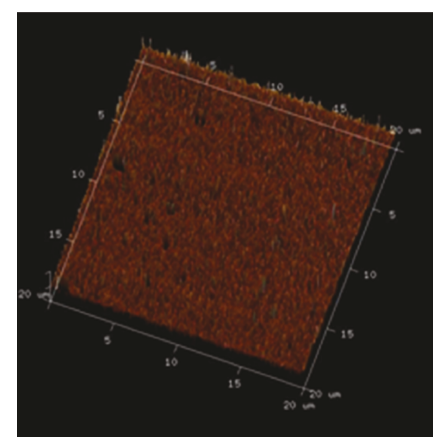

(d)

FIGURE 8: Gold surface substrate AFM images: (a) functionalized gold substrate, (b) gold substrate with immobilized cDNA, (c) gold substrate with immobilized cDNA and hybridized with the specific oligonucleotides, and (d) after digestion of cDNA with DNase I.

the sensor and allowed to hybridize to the probes on the chip. After, streptavidin magnetic nanoparticles were added to the sample in order to amplify the signal. The authors concluded that cell line DNA had certain concentration through qPCR standard curve analysis, which was confirmed with GMR analysis [10]. Meanwhile, Davis et al. reported an acoustic biosensor using, in order to bind DNA to the quartz crystal microbalance a neutravidin-modified device surface, which allows the binding of biotinylated-DNA molecules. They specifically designed sets of primers biotinylated at the $5^{\prime}$ end and used as template cDNA obtained from rat liver with and without treatment, in a multiplexed PCR reaction, which produced two different DNA fragments that were loaded on the neutravidin-covered acoustic device surface. Finally, the acoustic ratio was directly measured reflecting the mass ratio of the two immobilized fragments [12]. Instead, in the present work, the RNA sample employed was obtained from the blood samples of children with obesity and transcribed to cDNA, which is a more stable molecule to work with. The cDNA used in our experiments as target in the biosensor is a faithful, freelabeled copy of the patients genomic DNA. A key feature in biosensor development is the target used. To our knowledge, this is the first report of a biosensor developed with human cDNA as target, as well as the first biosensor designed to identify gene transcripts and their expression, from children with obesity. This biosensor could be applied for the molecular diagnosis of several pathologies.

Obesity is a state of chronic inflammation characterized by the expression of molecules related with proinflammatory processes such as the inflammasome. Inflammasome-type components depend on a specific antagonist or stimulation involved, but the final result of all inflammasomes is the assembly and activation or maturation of pro-IL-1b and pro-IL-18 active forms, through the Caspase 1 pathway 


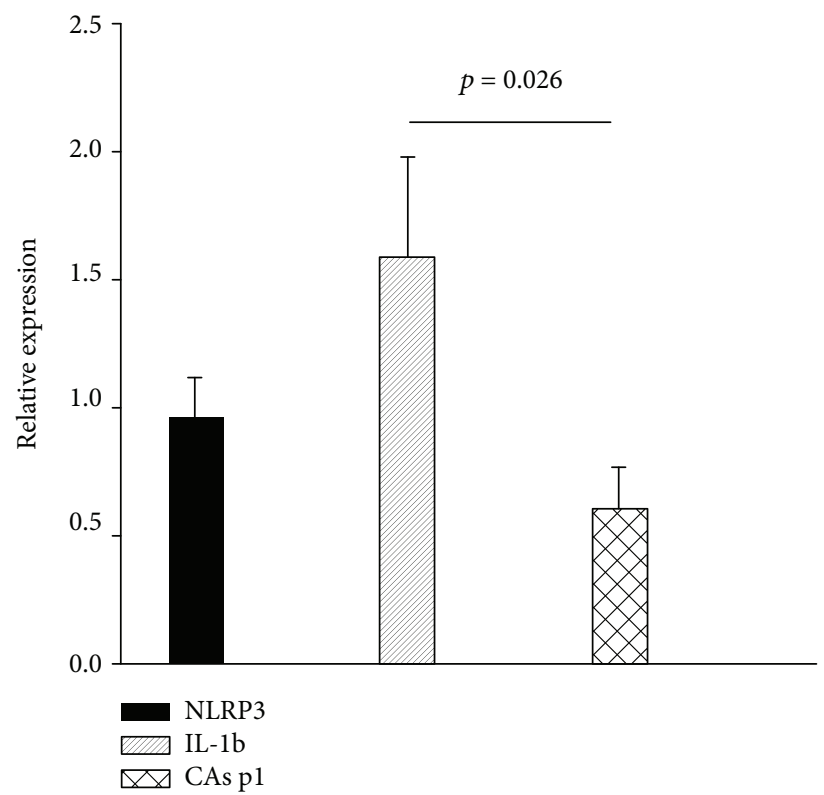

(a)

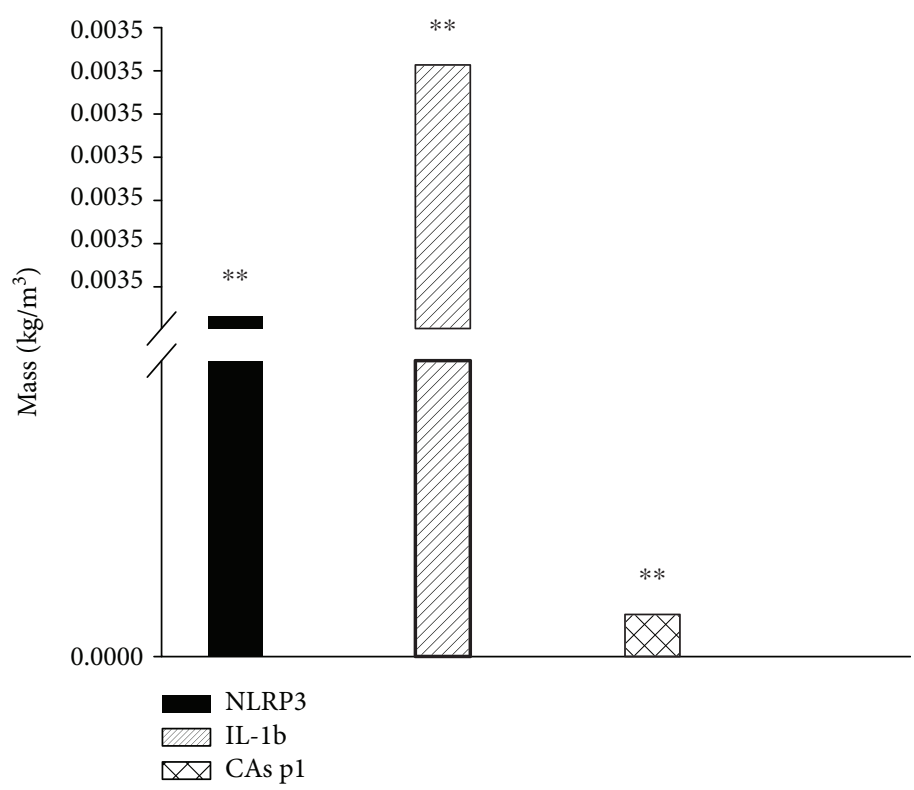

(b)

FiguRE 9: $N L R P 3, I L-1 \beta$, and CASP-1 gene expression. Each bar represents the average of 20 individuals. Graph (a) reveals the results of $N L R P 3, I L-1 \beta$, and CASP-1 gene expressions. Graph (b) depicts the deposited mass obtained from the QCM-D experiments.

[29-33], finding differences among all components. It has been described that Caspase 1 presents high expression in adipose animal tissue and in humans with obesity [30,34], possessing a very important function in determining inflammatory characteristics in human adipose tissue [35]. Due to the importance of these inflammatory molecules in human adipose tissue, in this work, QCM-D was utilized to determine the hybridization of five different genes; three of these were target genes (NLRP $3, I L-1 \beta$, and CASP-1), a positive control (the 18s constitutive gene), and a negative control (NLRP10, which is exclusively expressed in rats), thus proving the functionalization previously developed by our working group (patent pending, MX/E/2014/057816). The novelty of the functionalization as well as the biosensor described in this study is precisely the ability to immobilize cDNA or DNA obtained directly from human samples, without any label or chemical modification. This allows the identification of specific genes for the molecular diagnostic of pathologies as cancer, hypertension, and diabetes among others. The cDNA used in our experiments as capture probe in the biosensor is a faithful copy of the patient genomic DNA. Once the cDNA is synthesized, it is used as capture probe without any label or chemical modification, allowing to spend less time in the development and use of the 
biosensor. Previous works have reported the immobilization of double-stranded calf thymus DNA, purchased from a laboratory [36]; nonetheless, the majority of the probes used in biosensors are linear oligonucleotides, in the order of 18-25 bases synthesized in situ, presynthesized or hairpin oligonucleotides. Furthermore, peptide nucleic acids (PNAs) and locked nucleic acids (LNAs) have also been used as capture probes. PNAs are DNA mimics in which the bases are attached to a neutral N-(2-aminoethyl)-glycine pseudopeptide backbone, and LNAs are nucleic acid analogues in which the ribose ring is "locked" by a methylene bridge that shows increased thermal stability [4]. Other capture probes used are chemically modified at one of the oligonucleotide ends, and usually, biotin, thiol, or amine residues are aggregated, biotin and thiol being the most used chemical modifications $[7-9,37-40]$. Moreover, the surface chemistry used in this study enabled the immobilization of cDNA, which allowed developing a biosensor for gene expression determination from children with obesity. Besides being a proof of concept, this is the first biosensor of this type reported.

The results show that it is possible to detect the immobilized cDNA obtained from human RNA, since the QCM-D reports an increase in the deposited mass, as well as a decrease in the frequencies in nearly all of the genes studied, except for the negative control, in which no significant differences were found when hybridization with the specific oligonucleotides took place. Table 2 compares the frequency changes monitored during hybridization measurements for each of the assayed genes. These results are in agreement with the ones reported for QCM-D experiments; upon addition of a biomolecule, a rapid frequency decrease is observed, due to mass increase. Also, an increase in dissipation is reported [41]. Analysis of the corresponding results of the mass detected for each of the genes demonstrated a major detected mass for $I L-1 \beta$, followed by similar NLRP 3 and constitutive gene (18s) concentrations and a smaller concentration for CASP-1. These results suggest that $I L-1 \beta$ could be the molecule with greatest expression because it has the greater amount of mass, followed by NLRP3. On the other hand, the increase in dissipation is related to a viscoelasticity increase. It has been reported that when DNA is hybridized with its complementary strand, an increase of dissipation due to the stiffening of the DNA is observed [42]. This stiffening has to do with the hydrogen bond formation and hydration that occurs when complementary DNA strands are hybridizing, making the double-stranded DNA more stable [43]. The dissipation results obtained in this study are in agreement with these results; the QCM-D assays showed an increase in dissipation, for NLRP3, IL-1 $\beta$, and $C A S P-1$, when the hybridization took place. The number of molecules anchored and hybridized of each of the assayed genes was also calculated according to Thanh Ngo 2014. The results obtained for each of the genes agree with the amount of mass reported by the QCM-D. Surprisingly, when comparing mRNA gene expression results for $N L R P 3, I L-1 \beta$, and CASP-1 obtained with qPCR and QCM-D, similar patterns were found, revealing greatest expression of $I L-1 \beta$, followed by NLRP3, with CASP-1 being the molecule of least expression in the group of children with obesity.
TABLE 2: Average frequency changes \pm standard deviation monitored during hybridization measurements.

\begin{tabular}{lcc}
\hline Gene & cDNA & cDNA+primer \\
\hline NLRP3 & $-0.1833 \pm 0.1209$ & $-9.5833 \pm 0.1668$ \\
IL-1 $\beta$ & $-2.6433 \pm 0.3163$ & $-13.9783 \pm 0.1833$ \\
Casp1 & $2.7633 \pm 0.1369$ & $-3.12 \pm 0.22166$ \\
18s & $-3.4316 \pm 0.2341$ & $-4.705 \pm 0.2132$ \\
NLRP10-Rat & $-251.545 \pm 0.6081$ & $-264.495 \pm 0.7608$ \\
\hline
\end{tabular}

These results are important, because gene expression in children with obesity was obtained with very similar patterns between two different methods: a novel cDNA QCM-D biosensor and a validated method used in molecular biology, qPCR. These results also demonstrate that qPCR is a validation technique for QCM-D when working with gene expression. A possible explanation for these results is that the transcription reaction was done with random hexamer primers, as specified under Methods; the use of these primers allows transcription of all the mRNAs present in the sample, making it possible to detect greater expression of a transcript. The probes that are being detected by QCM are the cDNA transcripts to which the specific oligonucleotides are completely binding. This union allows the identification of gene transcripts through frequency changes in the QCM, exploiting the principle of hybridization of complementary DNA strands, without the use of the enzyme Taq polymerase and the fluorophores that are normally employed in qPCR for gene expression quantification. Gene expression is identified when a higher number of oligonucleotides are attached to the cDNA transcripts bonded in the quartz when hybridizing. Nevertheless, the experiments were repeated three times for each assayed gene, the stability was proven at the beginning of each QCM-D experiment when the fundamental lectures were taken, and the sensitivity was determined since the QCM-D was able to find different expression levels for each of the analyzed genes and these corresponded with the expression levels determined by qPCR.

At present, AFM comprises a powerful tool employed in the structural study of biological macromolecules such as proteins and DNA. It allows for visualization of these molecules and its complexes deposited over a surface with nanometer resolution, preserving their native structure [44]. AFM has been utilized to characterize protein-protein and protein-DNA interactions and conformations; it also allows determining the specificity of proteins binding to specific sites on DNA [45, 46]. Due to these features, AFM was used in this work to explore the changes occurring on the surface of the quartz crystal during DNA immobilization and hybridization processes. As well as in the work reported by Beckwitt's group, AFM imaging of anchored cDNA reveals "worm-like" features on top of the gold surface. These "worm-like" features disappear when the quartz crystal is treated with DNase I. Both in the present study and in those reported by other groups, AFM is a proven technique that provides advantages in terms of the imaging and characterization of DNA biosensors, allowing direct, label- 
free imaging at the single-molecule level of the process being undergone [46].

\section{Conclusions}

In conclusion, QCM-D can be used for determining the gene expression of transcripts in children with obesity, with similar results as the ones obtained with $\mathrm{qPCR}$, a validated method used in molecular biology to determine genic expression quantification. To our knowledge, this is the first work that identifies gene transcripts and their expression utilizing a biosensor such as QCM-D, in children with obesity. In addition, this work compares both the use of biosensors and a classical molecular biology technique to validate the former, obtaining amazingly similar values. The surface chemistry, which was previously designed by our working group, proved to be useful for cDNA immobilization. The QCM-D biosensor developed by our group was successful in gene expression determination, as proof of concept, using qPCR as validation method. This QCM-D biosensor despite being a proof of concept presents sensitivity, since expression level differences for each of the tested genes were detected, reusability, and stability, as well as in situ and nearly realtime monitoring. Furthermore, QCM-D decreases costs compared with a validated molecular biology technique, as qPCR. Further studies are needed to demonstrate the reproducibility of QCM-D as a novel technique for gene expression determination, using different samples and specific oligonucleotides for hybridization. Meanwhile, gene expression determination experiments with QCM-D require to validation with traditional molecular biology techniques, as qPCR.

\section{Abbreviations \\ QCM-D: Quartz crystal microbalance with dissipation monitoring \\ qPCR: Real time quantitative polymerase chain reaction \\ NLRP3: INFLAMMASOME NLRP3 gene (subset of the NLR family) \\ IL-1 3 : INTERLEUKIN $1 B$ gene \\ CASP-1: CASPASE 1 gene \\ DNA: Deoxyribonucleic acid \\ RNA: Ribonucleic acid \\ mRNA: Messenger ribonucleic acid \\ AFM: Atomic force microscopy.}

\section{Data Availability}

The data used to support the findings of this study are available from the corresponding author upon request.

\section{Ethical Approval}

This protocol was approved by the Ethics and Research Committees of the Escuela Superior de Medicina (ESM-CE01/03-12-2013). The trial was conducted in accordance with the ethical principles originating in the Declaration of Helsinki and it was consistent with Good Clinical Practice Guidelines.

\section{Consent}

Written and informed consent was obtained from all participants.

\section{Conflicts of Interest}

The authors declare that they have no conflict of interests.

\section{Authors' Contributions}

MGL, NMPV, HGM, and AMG participated in the conception and design of study. MGL, NMPV, and HGM collected the QCM-D and qPCR data. MGL, NMPV, AMG, CB, and MCGT did the analysis and/or interpretation of data. MGL, NMPV, and CB wrote the manuscript. AMG and ELP revised critically the study and the manuscript. All the authors gave approval for the submission. María Cristina González Torres and Ángel Miliar-García contributed equally to this work.

\section{Acknowledgments}

The present study was performed with the support of the Instituto Politécnico Nacional through the SIP and the Escuela Superior de Medicina, where molecular biology analyses were performed and QCM-D analysis was carried out in Centro de Nanociencias y Micro y Nanotecnologías. MGL, AMG, NMPV, ELP, HGM, and MCGT are SNI fellows. MGL was supported by a postdoctoral fellowship from CONACYT (246595).

\section{Supplementary Materials}

Results related viscoelasticity changes upon cDNA hybridization, viscoelasticity of the immobilized cDNA, and viscoelasticity of the immobilized cDNA plus the specific oligonucleotides, as well as the gene expression viscoelasticity is included in this section. (Supplementary Materials)

\section{References}

[1] R. Huang, P. Yi, and Y. Tang, "Probing the interactions of organic molecules, nanomaterials, and microbes with solid surfaces using quartz crystal microbalances: methodology, advantages, and limitations," Environmental Science: Processes \& Impacts, vol. 19, no. 6, pp. 793-811, 2017.

[2] L. Tedeschi, L. Ciiti, and C. Domenici, "An integrated approach for the design and synthesis of oligonucleotide probes and their interfacing to a QCM-based RNA biosensor," Biosensor and Bioelectronics, vol. 20, no. 11, pp. 2376-2385, 2005.

[3] F. Teles and L. Fonseca, "Trends in DNA biosensors," Talanta, vol. 77, no. 2, pp. 606-623, 2008.

[4] F. Lucarelli, S. Tombelli, M. Minunni, G. Marrazza, and M. Mascini, "Electrochemical and piezoelectric DNA biosensors for hybridisation detection," Analytica Chimica Acta, vol. 609, no. 2, pp. 139-159, 2008.

[5] J. Kankare, "Sauerbrey equation of quartz crystal microbalance in liquid medium," Langmuir, vol. 18, no. 18, pp. 7092-7094, 2002 . 
[6] P. Jearanaikoon, P. Prakrankamanant, C. Leelayuwat, S. Wanram, T. Limpaiboon, and C. Promptmas, "The evaluation of loop-mediated isothermal amplification-quartz crystal microbalance (LAMP-QCM) biosensor as a real-time measurement of HPV16 DNA," Journal of Virological Methods, vol. 229, pp. 8-11, 2016.

[7] W. Song, X. Guo, W. Sun, W. Yin, P. He, and X. Yang, “Targettriggering multiple-cycle signal amplification strategy for ultrasensitive detection of DNA based on QCM and SPR," Analytical Biochemistry, vol. 553, pp. 57-61, 2018.

[8] K. Bunroddith, N. Viseshakul, K. Chansiri, and P. Lieberzeit, "QCM-based rapid detection of PCR amplification products of Ehrlichia canis," Analytica Chimica Acta, vol. 1001, pp. 106-111, 2018.

[9] N. Ravi, G. Rizzi, E. S. Chang, P. Cheung, P. J. Utz, and S. X. Wang, "Quantification of cDNA on GMR biosensor array towards point-of-care gene expression analysis," Biosensors and Bioelectronics, vol. 130, pp. 338-343, 2019.

[10] J. Han, N. Yu, X. Ma, H. Bu, J. Xu, and H. Bu, "Reliable and quantitative electrochemical platform for direct detection of CYP707A1 gene expression from wheat leaves," Sensors and Actuators B: Chemical, vol. 279, pp. 274-280, 2018.

[11] G. Papadakis, A. Tsortos, A. Kordas et al., "Acoustic detection of DNA conformation in genetic assays combined with PCR," Scientific Reports, vol. 3, no. 1, 2013.

[12] B. K. Davis, H. Wen, and J. P. Ting, "The inflammasome NLRs in immunity, inflammation, and associated diseases," Annual Review of Immunology, vol. 29, no. 1, pp. 707-735, 2011.

[13] V. Štich, "Adaptation of adipose tissue to weight-reduction energy-restricted diet in obese individuals," Vnitřní Lékařství, vol. 62 , pp. 123-128, 2016.

[14] J. C. Tapia-Rivera, L. M. Baltazar-Rodríguez, M. I. CárdenasRojas et al., "The rs4285184 polymorphism of the MGAT1 gene as a risk factor for obesity in the Mexican population," Medicina Clínica (English Edition), vol. 148, no. 4, pp. 149152, 2016.

[15] V. R. Hugo, L. M. Paola, R. M. K. Luis et al., "A combined linkage and association strategy identifies a variant near the GSTP1 gene associated with BMI in the Mexican population," Journal of Human Genetics, vol. 62, no. 3, pp. 413-418, 2016.

[16] N. J. Pillon, K. L. Chan, S. Zhang et al., "Saturated fatty acids activate caspase- $4 / 5$ in human monocytes, triggering IL- $1 \beta$ and IL-18 release," American Journal of Physiology Endocrinology and Metabolism, vol. 311, no. 5, pp. E825-E835, 2016.

[17] T. Kelly, W. Yang, C.-S. Chen, K. Reynolds, and J. He, "Global burden of obesity in 2005 and projections to 2030," International Journal of Obesity, vol. 32, no. 9, pp. 1431-1437, 2008.

[18] M. Pinti, V. Appay, J. Campisi et al., "Aging of the immune system: focus on inflammation and vaccination," European Journal of Immunology, vol. 46, no. 10, pp. 2286-2301, 2016.

[19] V. Rainone, L. Schneider, I. Saulle et al., "Upregulation of inflammasome activity and increased gut permeability are associated with obesity in children and adolescents," International Journal of Obesity, vol. 40, no. 6, pp. 1026-1033, 2016.

[20] Y. Zheng, D. Tuo, E. P. Leif et al., "Transcriptome analysis of human adipocytes implicates the NOD-like receptor pathway in obesity-induced adipose inflammation," Molecular and Cellular Endocrinology, vol. 394, no. 1-2, pp. 80-87, 2014.

[21] R. Julian, E. Eveliina, B. F. Jan et al., "miR-146a-mediated suppression of the inflammatory response in human adipocytes," Scientific Reports, vol. 6, no. 1, article 38339, 2016.
[22] A. Moeintaghavi, A. H. Reza, S. A. Rahim Rezaee et al., "The effects of smoking on expression of IL-12 and IL-1 $\beta$ in gingival tissues of patients with chronic periodontitis," The Open Dentistry Journal, vol. 11, no. 1, pp. 595-602, 2017.

[23] K. Von Kopylow, W. Schulze, A. Salzbrunn et al., "Dynamics, ultrastructure and gene expression of human in vitro organized testis cells from testicular sperm extraction biopsies," MHR: Basic science of reproductive medicine, vol. 24 , no. 3 , pp. 123-134, 2018.

[24] V. K. Thanh Ngo, D. Giang Nguyen, H. P. Uyen Nguyen et al., "Quartz crystal microbalance (QCM) as biosensor for the detecting of Escherichia coli O157:H7," Advances in Natural Sciences: Nanoscience and Nanotechnology, vol. 5, no. 4, article 045005, 2014.

[25] T. Shuntaro, T. Kentaro, U. Takuya, and O. Yoshio, “Traveling time of a translating ribosome along messenger RNA monitored directly on a quartz crystal microbalance," Journal of the American Chemical Society, vol. 134, no. 15, pp. 67936800, 2012.

[26] H. Matsuno, K. Niikura, and Y. Okahata, "Direct monitoring kinetic studies of DNA polymerase reactions on a DNAimmobilized quartz-crystal microbalance," Chemistry - A European Journal, vol. 7, no. 15, pp. 3305-3312, 2001.

[27] S. Takahashi, H. Matsuno, H. Furusawa, and Y. Okahata, "Kinetic analyses of divalent cation-dependent EcoRV digestions on a DNA-immobilized quartz crystal microbalance," Analytical Biochemistry, vol. 361, no. 2, pp. 210-217, 2007.

[28] S. Takahashi, M. Lida, H. Furusawa, Y. Shimizu, T. Ueda, and Y. Okahata, "Real-time monitoring of cell-free translation on a quartz-crystal microbalance," Journal of the American Chemical Society, vol. 131, no. 26, pp. 9326-9332, 2009.

[29] R. Stienstra, J. A. van Diepen, and C. J. Tack, "Inflammasome is a central player in the induction of obesity and insulin resistance," Proceedings of the National Academy of Sciences of the United States of America, vol. 108, no. 37, pp. 15324-15329, 2011.

[30] R. Stienstra, L. A. Joosten, T. Koenen et al., "The inflammasome-mediated caspase- 1 activation controls adipocyte differentiation and insulin sensitivity," Cell Metabolism, vol. 12, no. 6, pp. 593-605, 2010.

[31] Y. H. Youm, A. Adijiang, B. Vandanmagsar, D. Burk, A. Ravussin, and V. D. Dixit, "Elimination of the NLRP3ASC inflammasome protects against chronic obesity-induced pancreatic damage," Endocrinology, vol. 152, no. 11, pp. 4039-4045, 2011.

[32] B. Vandanmagsar, Y. H. Youm, and A. Ravussin, "The NLRP3 inflammasome instigates obesity-induced inflammation and insulin resistance," Nature Medicine, vol. 17, no. 2, pp. 179$188,2011$.

[33] H. Wen, D. Gris, and Y. Lei, "Fatty acid-induced NLRP3-ASC inflammasome activation interferes with insulin signaling," Nature Immunology, vol. 12, no. 5, pp. 408-415, 2011.

[34] R. W. Grant and V. D. Dixit, "Mechanisms of disease: inflammasome activation and the development of type 2 diabetes," Frontiers in Immunology, vol. 4, pp. 4-50, 2013.

[35] T. B. Koenen, R. Stienstra, L. J. van Tits et al., "Hyperglycemia activates caspase- 1 and TXNIP-mediated IL- $1 \beta$ transcription in human adipose tissue," Diabetes, vol. 60 , no. 2, pp. $517-$ $524,2011$. 
[36] P. R. Solanki, N. Prabhakar, M. K. Pandey, and B. D. Malhotra, "Self-assembled monolayer for toxicant detection using nucleic acid sensor based on surface plasmon resonance technique," Biomedical Microdevices, vol. 10, no. 5, pp. 757-767, 2008.

[37] S. R. Hong, H. D. Jeong, and S. Hong, "QCM DNA biosensor for the diagnosis of a fish pathogenic virus VHSV," Talanta, vol. 82, no. 3, pp. 899-903, 2010.

[38] L. Xu, W. Liang, Y. Wen et al., "An ultrasensitive electrochemical biosensor for the detection of mecA gene in methicillin-resistant Staphylococcus aureus," Biosensors and Bioelectronics, vol. 99, pp. 424-430, 2018.

[39] H. Zhang, Y. Yang, H. Dong, and C. Cai, "A superstructurebased electrochemical assay for signal-amplified detection of DNA methyltransferase activity," Biosensors and Bioelectronics, vol. 86, pp. 927-932, 2016.

[40] M. Manzano, S. Viezzi, S. Mazerat, R. S. Marks, and J. Vidic, "Rapid and label-free electrochemical DNA biosensor for detecting hepatitis A virus," Biosensors and Bioelectronics, vol. 100, pp. 89-95, 2018.

[41] H. Fredrik, R. Michael, K. Bengt, and P. Brzezinski, "Structural changes in hemoglobin during adsorption to solid surfaces: effects of $\mathrm{pH}$, ionic strength, and ligand binding," Proceedings of the National Academy of Sciences of the United States of America, vol. 95, no. 21, pp. 12271-12276, 1998.

[42] G. W. Jakob, B. Karl, S. Sofia, and A. Bo, "Reversible hybridization of DNA anchored to a lipid membrane via porphyrin," Langmuir, vol. 28, no. 4, pp. 1944-1953, 2011.

[43] S. Muttaiya and P. Baocheng, "Hydrogen and hydration of DNA and RNA oligonucleotides," Biophysical Chemistry, vol. 95, no. 3, pp. 273-282, 2002.

[44] O. Medalia, J. Englander, R. Guckenberger, and J. Sperling, "AFM imaging in solution of protein-DNA complexes formed on DNA anchored to a gold surface," Ultramicroscopy, vol. 90, no. 2-3, pp. 103-112, 2002.

[45] S. LeBlanc, H. Wilkins, Z. Li, P. Kaur, H. Wang, and D. A. Erie, "Using atomic force microscopy to characterize the conformational properties of proteins and protein-DNA complexes that carry out DNA repair," Methods in Enzymology, vol. 592, pp. 187-212, 2017.

[46] E. Beckwitt, M. Kong, and B. Van Houten, "Studying proteinDNA interactions using atomic force microscopy," Seminars in Cell \& Developmental Biology, vol. 73, no. 220, pp. 220230, 2017. 


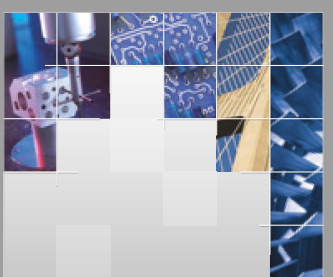

\section{Enfincering}
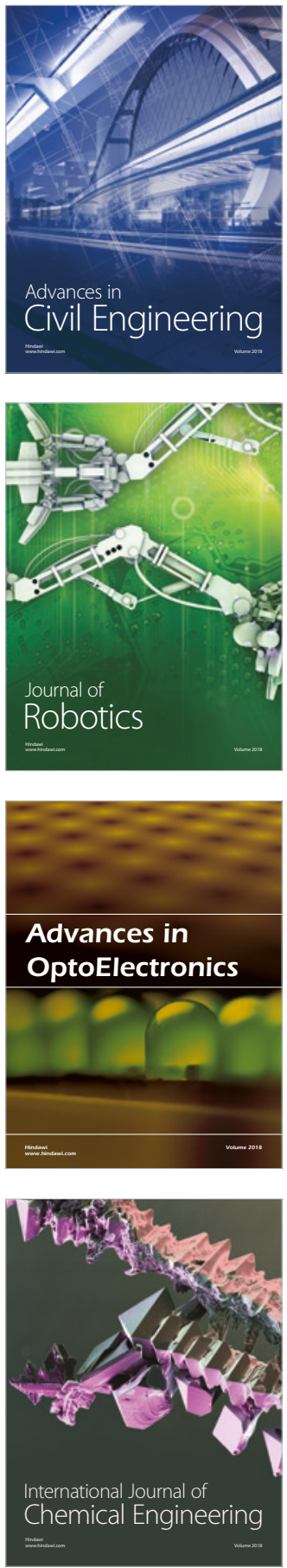

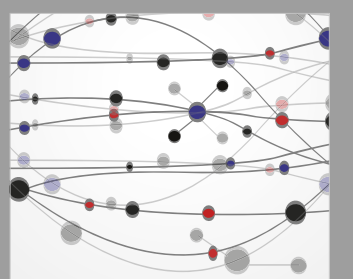

\section{Rotating \\ Machinery}

The Scientific World Journal

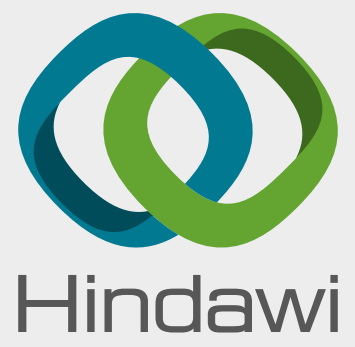

Submit your manuscripts at

www.hindawi.com
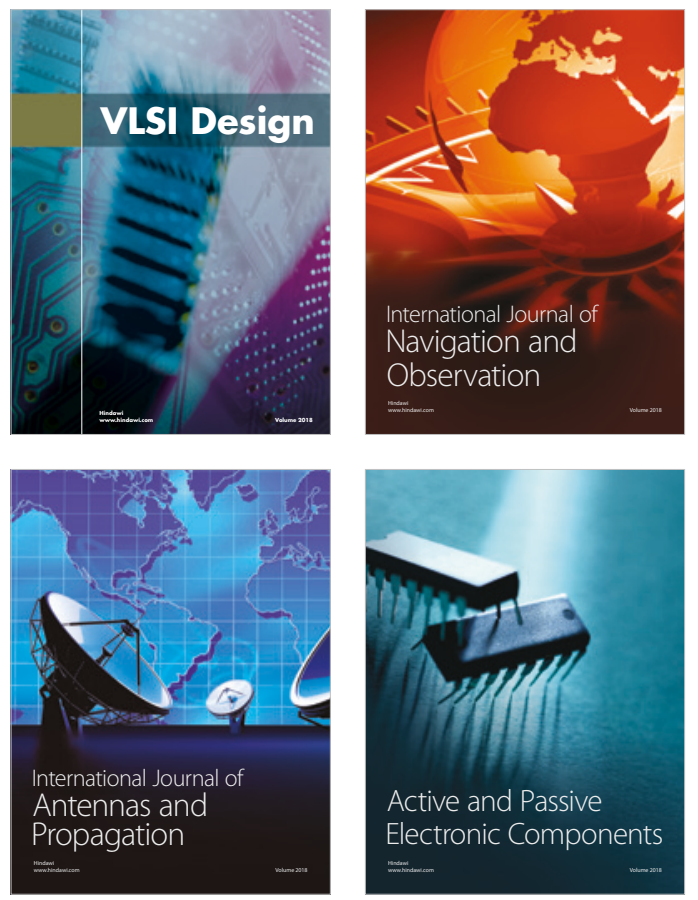
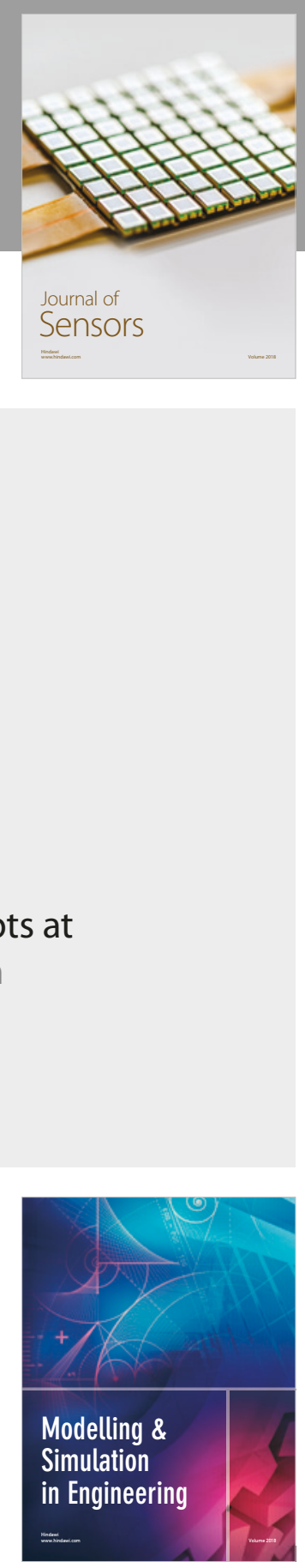

\section{Advances \\ Multimedia}
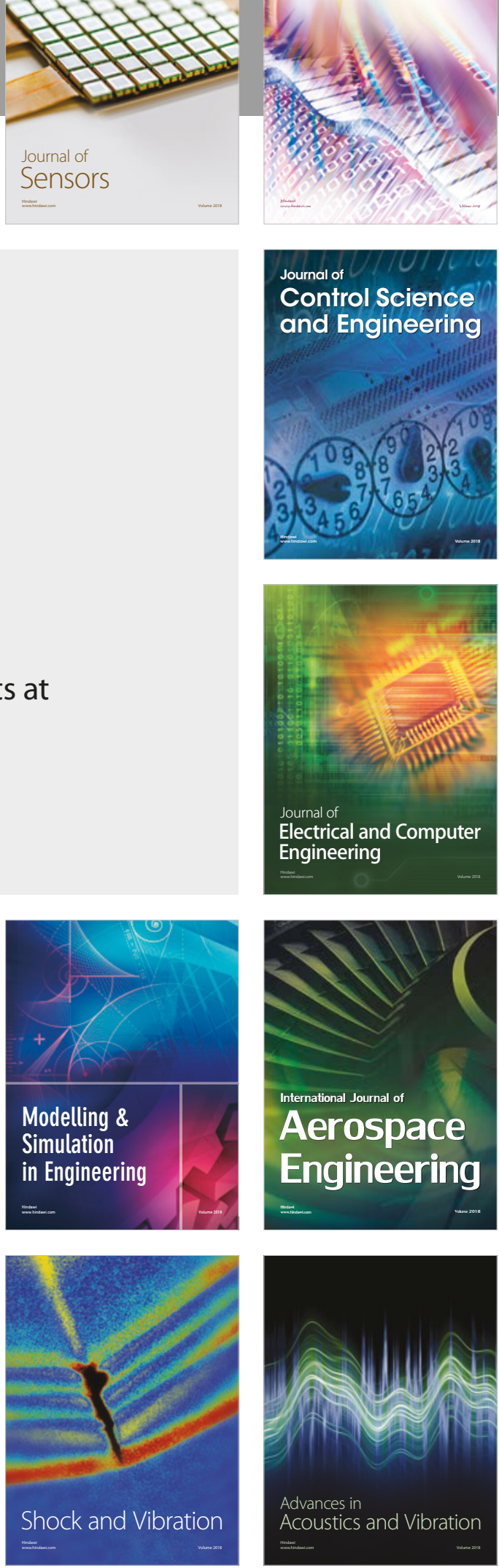